\title{
Financial Liberalization and Managing Interest Rate Risk in China
}

\author{
Wang Minchao \\ School of Economics, Shanghai University, Shanghai, China
}

\section{Email address:}

wang_minchao@hotmail.com

\section{To cite this article:}

Wang Minchao. Financial Liberalization and Managing Interest Rate Risk in China. Science Innovation. Vol. 4, No. 4, 2016 , pp. $205-210$. doi: 10.11648/j.si.20160404.16

Received: September 23, 2016; Accepted: October 10, 2016; Published: October 13, 2016

\begin{abstract}
Commercial Banks in the modern society, has the core status. Under today's social environment, interest rate marketization has become the choice of most countries. Commercial Banks also face new risks in this context--interest rate risk. The common risk has become the problem that the development of the commercial Banks and even the entire financial development must face. In this paper, I use the method of empirical analysis eviews software to quantitative analyze the interest rate risk of commercial Banks in China. The results show that under the contemporary background, the bank's overall interest rate risk is high and some problems such as some banks' lacking ability to resist risk. For such a situation, banks should put forward to strengthen supervision, enhance the consciousness of the interest rate risk management, improve the pricing system and the introduction of international advanced interest rate risk management, improve the interest rate risk management talent introduction and cultivation mode.
\end{abstract}

Keywords: Commercial Banks, Interest Rate, Risk

\section{利率市场化下中国商业银行利率风险管理研究}

\section{王敏超}

经济学院, 上海大学, 上海, 中国

邮箱

wang_minchao@hotmail.com

摘要：商业银行在现代社会来讲有着十分核心的地位，如今的金融大环境下，利率市场化已经成为多数国家的选择， 而在这种环境下，商业银行也面临着新的风险一一利率风险。这种普遍的风险是商业银行发展乃至整个金融界发展必 须面临的问题。本文通过eviews软件实证分析的方法定量分析了中国商业银行面临的利率风险问题, 发现在当代背景 下, 利率风险正在升高并且存在银行抵御风险能力下降等问题, 对于这样的现状, 提出了加强监管, 强化利率风险管 理意识、完善产品定价体系、引入国际先进的利率风险管理、完善利率风险管理专业人才引进和培养模式等建议。

关键词：商业银行，利率，风险 


\section{1. 引言}

随着世界经济一体化以及科技创新日新月异, 金融效 率得到极大提升, 金融市场发生了本质变化。利率成为现 代经济和金融的核心，其通过影响货币市场与资本市场， 进而影响一国经济。

从这一关系中我们可以看出利率对于经济的发展的 重要性。我国在一开始实行利率管制政策, 因此利率风险 问题一直比较隐秘, 也一直没有引起人们的重视, 但是随 着时代的变迁我国也跟随国际浪潮实行了利率市场化, 这 也直接导致利率风险问题成为每个商业银行都必须面临 的问题, 利率风险研究、利率风险的正确防范, 正在成为 我国商业银行乃至整个金融界必须面临的问题。

国内在利率市场化方面的研究论著很多, 尤其是上世 纪90年始, 随着利率市场化改革快速发展推进, 利率市场 化理论与实践研究成为一个重要的领域。王晋斌、于春海 (2012) 在分析了利率市场化中的实质性问题以及利率市 场化对商业银行的影响后, 提出了利率市场化的可能路径。 肖欣荣 (2012) 通过分析利率市场化对美国银行业的影响, 提出利率市场化需要渐进式推进, 利率放权不宜过快。武 剑 (2013) 将利率风险的成为归纳为内部成因和外部成因, 外部成因诸如经济形势变化、宏观政策转变、金融市场波 动等, 内部成因诸如资产负债结构失衡、技术手段落后、 利率风险管理体制不合理等。邵伏军 (2014) 根据风险范 围的大小, 将利率市场化改革风险分为微观风险和宏观风 险。并认为如果一国能够为利率市场化改革营造一个宽松 的经济环境, 并且遵循循序渐进的原则, 尽量避免微观风 险的发生或是在微观风险发生以后能够有效控制其扩散 和蔓延, 那么宏观风险发生的可能性就会大大降低。郭慧 宇（2015）经过实证检验发 现 ARMA $(1,1)-$ $\operatorname{EGARCH}(1,1)-G E D$ 模型能够很好地描述我国隔夜Shibor对 数收益率的特征; 经过该模型过滤计算的日均VaR均通过 LR回测检验, 该模型有效的度量了Shibor收益率的风险。 钱聿瑾 (2015) 选择基于Garch模型的VaR计算和利率敏感 性缺口模型作为实证研究方法。研究结果表明当前银行整 体的利率风险偏高, 多数银行存在短期负缺口现象, 国有 商业银行的期限错配问题严重。为防范利率上行对短期收 益的不利影响, 银行应调整资产负债结构以缩小短期缺口 值。

本文试图通过Eviews软件, 通过实证分析的方法分析 商业银行面临的利率风险的问题, 研究商业银行如何面对 现代利率风险问题。利率风险问题不仅仅是商业银行自己 的问题，而是整个金融界都必须离面临的风险，也正是因 为如此, 如果想要真有效预防利率风险, 就必须将银行和 政府两方面都纳入到防范主体当中, 各司其职, 真正做到 控制利率风险。

\section{2. 数据选取与分析}

\section{1. 数据来源}

上海银行间同业拆放利率 (SHIBOR) 是于 2007 年 1 月 4 日正式开始运行并对外公布数据的。本文选取的数据以
2006年10月 8 日至2016年6月 30 日隔夜拆借利率为样本进 行观测, 样本数据共 2434 个。

\section{2. 数据分析方法}

GARCH模型基本原理为: 设 $x_{t}$ 的自回归 $\mathrm{AR}(\mathrm{p})$ 形式为

$$
x_{t}=\beta_{0}+\beta_{1} x_{t-1}+\beta_{2} x_{t-2}+\cdots+\beta_{p} x_{t-p}+u_{t}
$$

则随机误差项 $u_{t}$ 的方差的方差为

$$
\operatorname{Var}\left(u_{t}\right)=\sigma_{t}^{2}=E\left(u_{t}^{2}\right)=\sigma_{0}+\sigma_{1}+\sigma_{2}+\cdots+\sigma_{q}+\varepsilon_{t}
$$

其中, 回归模型的参数 $\sigma_{0}, \sigma_{1}, \cdots, \sigma_{q}$ 均为非负数, 这样才能保证方差 $\sigma_{t}^{2}$ 为正。

我们称这里的随机误差项 $u_{t}$ 服从 $\mathrm{q}$ 阶的 $\mathrm{ARCH}$ 过程, 记 作 $u_{t} \sim \mathrm{ARCH}$ (q)。

GARCH (1, 1) 模型是比较常用的一种, 括号中的第 一个数值为 $\mathrm{GARCH}$ 项的阶数, 第二数值为 $\mathrm{ARCH}$ 项的阶数。 其基本形式为:

$$
\sigma_{t}^{2}=\beta_{0}+\beta_{1} u_{t-1}^{2}+\beta_{2} u_{t-1}^{2}
$$

GARCH (1，1）模型在金融领域应用广泛，可以对金 融时间序列的数据进行描述。

当上述辅助回归方程进行ARCH效应检验时, 如果ARCH 的滞后阶数 $q$ 很大, 检验结果依然显著, 即残差序列依然 存在ARCH $(q)$ 效应。此时可采用GARCH $(p, q)$ 模型重新 进行估计。

\section{3. 数据检验}

\subsection{1. 正态性检验}

数据符合正态性检验是进行分析的必要条件, 也只有 满足了这个条件才能进一步进行分析建模。

使用Eviews软件对于数据进行正态性检验, 检验结果 如图:
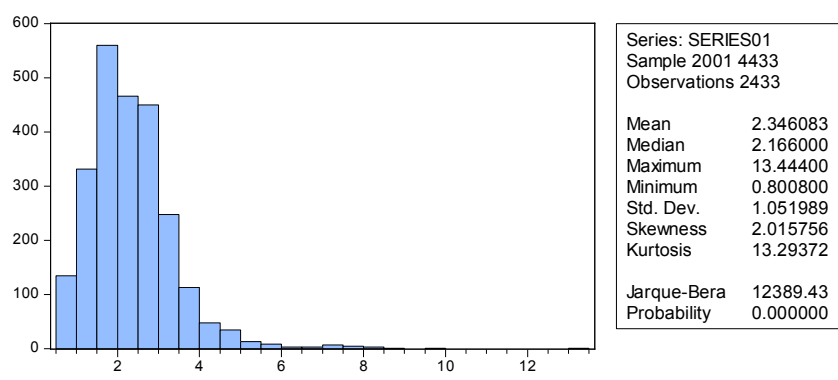

图1 正态性检验结果。

由图1直方图可知，同业拆借利率分布偏度系数 2.02 大于零, 为右偏分布; 在直方图中可以看出具有较长的左 尾和右尾, 且左尾明显厚于右尾; 峰度值13.29372明显大 于正态分布峰度值 3 , 为尖峰分布。 


\subsection{2. 自相关性检验}

自相关性检验是进行模型建模的必要条件, 主要是进 行通过收益率序列滞后各期的自相关系数 (AC)、偏相关系 数 $(P A C)$ 来及 $Q$ 统计量等来判断该序列的是否存在自相关。 使用Eviews软件进行自相关性检验，检验结果可以用下表 来表示:

表1 自相关性检验结果。

\begin{tabular}{|c|c|c|c|c|}
\hline & $\mathrm{AC}$ & PAC & Q-Stat & Prob \\
\hline 1 & 0.941 & 0.941 & 2155.3 & 0.000 \\
\hline 2 & 0.878 & -0.060 & 4033. 4 & 0.000 \\
\hline 3 & 0.827 & 0.072 & 5701.4 & 0.000 \\
\hline 4 & 0.784 & 0.032 & 7200.6 & 0.000 \\
\hline 5 & 0.743 & -0.002 & 8546.4 & 0.000 \\
\hline 6 & 0.712 & 0.076 & 9782.1 & 0.000 \\
\hline 7 & 0.687 & 0.039 & 10934 & 0.000 \\
\hline 8 & 0.655 & -0.061 & 11982 & 0.000 \\
\hline 9 & 0.627 & 0.042 & 12943 & 0.000 \\
\hline 10 & 0.607 & 0.044 & 13843 & 0.000 \\
\hline 11 & 0.595 & 0.070 & 14707 & 0.000 \\
\hline 12 & 0.582 & 0.006 & 15535 & 0.000 \\
\hline 13 & 0.570 & 0.019 & 16330 & 0.000 \\
\hline 14 & 0.560 & 0.027 & 17098 & 0.000 \\
\hline 15 & 0.552 & 0.035 & 17845 & 0.000 \\
\hline 16 & 0.552 & 0.088 & 18594 & 0.000 \\
\hline 17 & 0.558 & 0.064 & 19358 & 0.000 \\
\hline 18 & 0.565 & 0.033 & 20141 & 0.000 \\
\hline 19 & 0.572 & 0.047 & 20943 & 0.000 \\
\hline 20 & 0.575 & 0.009 & 21756 & 0.000 \\
\hline 21 & 0.572 & -0.022 & 22559 & 0.000 \\
\hline 22 & 0.562 & -0.023 & 23336 & 0.000 \\
\hline 23 & 0.548 & -0.040 & 24075 & 0.000 \\
\hline 24 & 0.531 & -0.032 & 24767 & 0.000 \\
\hline 25 & 0.511 & -0.019 & 25410 & 0.000 \\
\hline 26 & 0.493 & 0.000 & 26009 & 0.000 \\
\hline 27 & 0.479 & 0.025 & 26575 & 0.000 \\
\hline 28 & 0.466 & -0.009 & 27109 & 0.000 \\
\hline 29 & 0.457 & 0.048 & 27625 & 0.000 \\
\hline 30 & 0.452 & 0.019 & 28129 & 0.000 \\
\hline 31 & 0.448 & 0.018 & 28624 & 0.000 \\
\hline 32 & 0.444 & 0.019 & 29111 & 0.000 \\
\hline 33 & 0.442 & 0.014 & 29594 & 0.000 \\
\hline 34 & 0.442 & 0.018 & 30076 & 0.000 \\
\hline 35 & 0.439 & -0.003 & 30553 & 0.000 \\
\hline 36 & 0.438 & 0.003 & 31026 & 0.000 \\
\hline
\end{tabular}

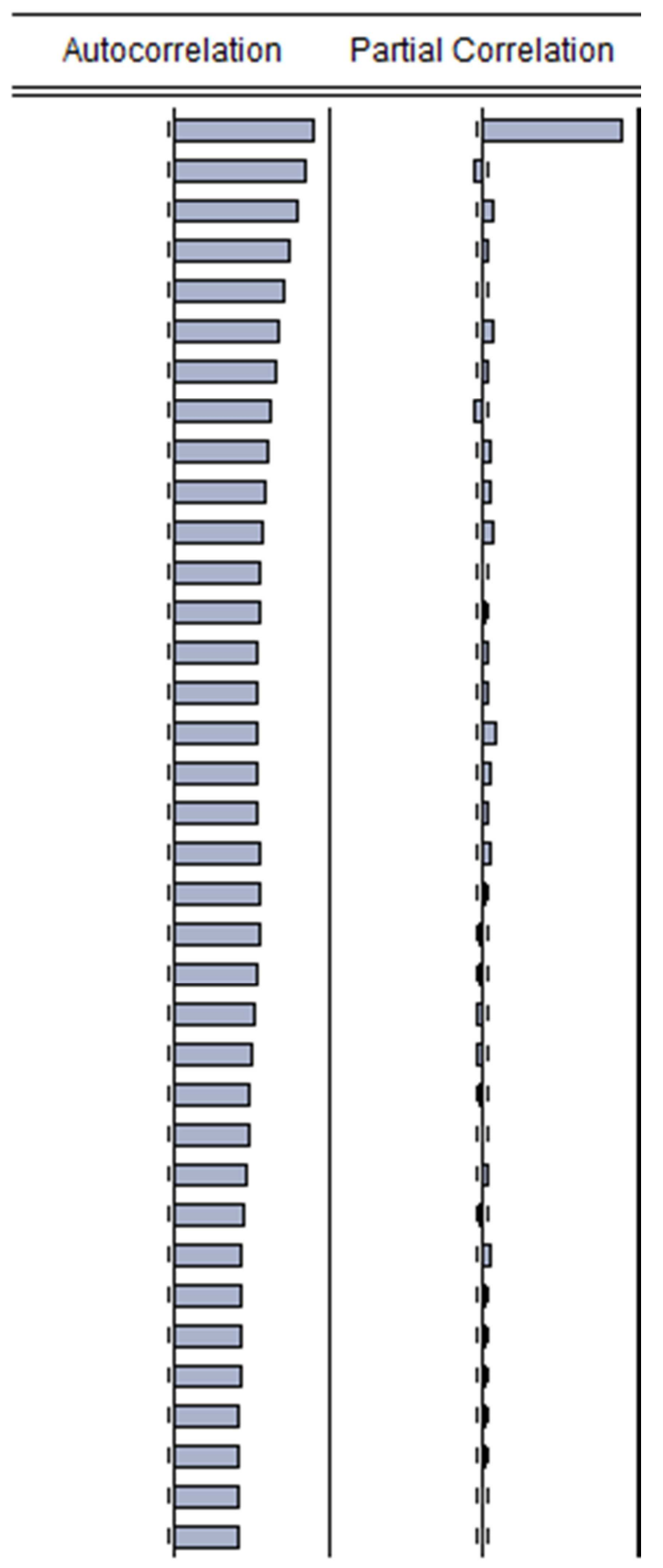

图2 自相关性检验结果（续）。

相关检验结果可知自相关系数和偏相关系数都不等 于零，因此可以判断收益率序列的存在序列自相关。

\section{4. 建立GARCH模型}

我们从上文的研究中不难发现, 选取的SHIBOR数据序 列已经完全满足建立GARCH模型的条件，所以下一步就是 对于数据进行建模操作。首先根据序列的偏自相关和自相 关系数建立AR ( $p$ ) 作为 $\mathrm{GARCH}$ 模型的均值方程, 然后用 $\operatorname{GARCH}(1,1)$ 拟合扰动方程, 其中残差分布假设是T分布, 最后计算 $V a R$ 值。对SHIBOR用GARCH $(1,1)$ 一正态分布模 型进行估计，经过回归得到: 
表2 自相关性检验结果。

\begin{tabular}{|c|c|c|c|c|}
\hline$\frac{\text { Dependent Variable: }}{\text { Method: ML - ARCH }}$ & distribution & & & \\
\hline Date: $08 / 21 / 16 \quad \mathrm{Ti}$ & & & & \\
\hline Sample (ad justed): & & & & \\
\hline Included observatio & stments & & & \\
\hline Convergence achieve & & & & \\
\hline Presample variance: & $r=0.7)$ & & & \\
\hline GARCH $=\mathrm{C}(1)+\mathrm{C}(2)$ & $* \operatorname{GARCH}(-1)$ & & & \\
\hline Variable & $\begin{array}{l}\text { Coefficient } \\
\text { Variance Equation }\end{array}$ & Std. Error & z-Statistic & Prob. \\
\hline $\mathrm{C}$ & 0.029063 & 0.001250 & 23. 25727 & 0.0000 \\
\hline $\operatorname{RESID}(-1)^{\wedge} 2$ & 0.856461 & 0.040599 & 21. 09547 & 0.0000 \\
\hline $\operatorname{GARCH}(-1)$ & 0.153427 & 0.019250 & 7.970245 & 0.0000 \\
\hline R-squared & 0.000000 & Mean depen & & 2. $72 \mathrm{E}-07$ \\
\hline Adjusted R-squared & 0.000411 & S. D. depen & & 1. 051989 \\
\hline S. E. of regression & 1. 051773 & Akaike inf & & 1.911061 \\
\hline Sum squared resid & 2691.447 & Schwarz cr & & 1.918209 \\
\hline Log likelihood & -2321.806 & Hannan-Qui & & 1. 913660 \\
\hline Durbin-Watson stat & 0.118706 & & & \\
\hline
\end{tabular}

根据分析结果, 可以得到条件方差方程: $\delta_{\mathrm{t}}=0.029063+0.856461 \mu+0.153427 \delta^{2}{ }_{\mathrm{t}-1}$

\section{5. 建立GARCH模型后检验}

进行建模后, 需要进行对于模型的拟合性优劣的检验, 只有通过检验的模型才能进行下一步计算, 模型的拟合性
的优劣决定了计算的准确性。采用ARCH-LM检验方法进行 检验, 检验结果如下:

先对SHIBOR滞后1阶的拆借利率序列进行普通最小二 乘估计, 然后根据得出的残差序列进行ARCH-LM检验（其 中, 滞后阶数为 3 ), 检验结果如表:

表3 ARCH-LM检验结果。

\begin{tabular}{|c|c|c|c|c|}
\hline \multicolumn{5}{|c|}{ Heteroskedasticity Test: ARCH } \\
\hline F-statistic & 0.840027 & Prob. $\mathrm{F}(1,2$ & & 0.3595 \\
\hline Obs*R-squared & 0.840411 & Prob. Chi- & & 0.3593 \\
\hline \multicolumn{5}{|l|}{ Test Equation: } \\
\hline \multicolumn{5}{|c|}{ Dependent Variable: WGT_RESID`2 } \\
\hline \multicolumn{5}{|c|}{ Method: Least Squares } \\
\hline \multicolumn{5}{|c|}{ Date: $08 / 15 / 16$ Time: $13: 50$} \\
\hline \multicolumn{5}{|c|}{ Sample (adjusted) : 10/10/2006 6/30/2016 } \\
\hline \multicolumn{5}{|c|}{ Included observations: 2538 after adjustments } \\
\hline Variable & Coefficient & Std. Error & t-Statistic & Prob. \\
\hline $\mathrm{C}$ & 0.981986 & 0.053953 & 18. 20092 & 0.0000 \\
\hline WGT_RESID^2 $(-1)$ & 0.018197 & 0.019854 & 0.916530 & 0.3595 \\
\hline $\mathrm{R}$-squared & 0.000331 & Mean depen & & 1. 000185 \\
\hline Adjusted $\mathrm{R}$-squared & -0.000063 & S. D. depen & & 2. 527194 \\
\hline S. E. of regression & 2. 527274 & Akaike inf & & 4. 692947 \\
\hline Sum squared resid & 16197.72 & Schwarz cr & & 4. 697549 \\
\hline Log likelihood & -5953.350 & Hannan-Quir & & 4. 694617 \\
\hline $\mathrm{F}$-statistic & 0.840027 & Durbin-Wat: & & 1. 999968 \\
\hline Prob(F-statistic) & 0.359476 & & & \\
\hline
\end{tabular}

根据结果所示, 在 $95 \%$ 显著性水平下接受原假设, 所 以GARCH $(1,1)$ 模型消除了残差序列的ARCH效应。也就说 明了该模型拟合效果较好, 可以进行下一步计算。

\section{6. 以GARCH模型为基础的 $\mathrm{VaR}$ 值计算}

根据得到的方程, 计算出条件方差估计值, 再对其开 方得到条件标准差估计值, 利用公式 $V a R=Z_{\alpha} \sigma_{t} S H I B O R_{t-1}-\mu$, 以此计算出每天的VaR值, 其 中选取 $a=0.05, Z_{a}=1.65$ 。
根据得到的条件方差方程, 计算出条件方差估计值, 再对其开方得到条件标准差估计值, 由此获得XX银行在同 业拆借 1 亿元的VaR值分别为:

$$
\mathrm{VaR}=14.4230134
$$

\section{7. 利润敏感性缺口在我国商业银行的应用分析}

选取国有商业银行 1 年内缺口统计表作为研究样本, 农业银行和光大银行因上市时间较短, 没有列入统计样本。 根据数据整理得到利率敏感性缺口分析报表如下: 
表 4 商业银行 1 年内缺口率统计表。

\begin{tabular}{llllllllllll}
\hline 商业银行1年内缺口率统计表 (单位: \%) \\
\hline & 2006 & 2007 & 2008 & 2009 & 2010 & 2011 & 2012 & 2013 & 2014 & 2015 & 平均值 \\
\hline 工商银行 & -8.97 & -13.70 & -11.29 & -0.83 & -6.19 & -5.89 & -1.14 & -1.86 & 0.49 & 0.48 & -4.89 \\
中国银行 & -5.91 & -6.03 & -1.85 & -0.07 & -1.27 & 0.15 & 1.98 & 2.29 & 2.24 & 2.52 & -0.59 \\
建设银行 & -7.10 & -10.78 & -2.50 & -2.60 & -5.55 & -4.87 & -0.14 & -1.32 & 0.17 & -0.79 & -3.55 \\
平安银行 & -3.74 & -2.54 & 2.20 & 2.30 & 0.86 & 3.26 & 0.96 & -2.10 & -1.41 & -5.08 & -0.53 \\
浦发银行 & 1.52 & 1.52 & 4.90 & 2.33 & 6.77 & 2.97 & 3.78 & -0.60 & -0.20 & -4.95 & 1.80 \\
华夏银行 & -2.11 & 2.87 & 1.28 & 2.59 & 1.38 & 2.29 & -6.38 & -8.85 & -8.75 & -10.01 & -2.57 \\
民生银行 & -3.51 & -4.36 & 4.21 & 1.54 & 1.99 & 2.41 & 8.88 & 4.13 & 1.43 & -0.03 & 1.67 \\
招商银行 & 2.86 & 0.14 & 1.20 & -1.23 & -1.35 & 0.35 & 1.85 & -0.74 & -2.54 & -2.17 & -0.16 \\
兴业银行 & -7.20 & -2.18 & 2.26 & -1.68 & 0.95 & 4.98 & 0.79 & -8.51 & -5.06 & -16.14 & -3.18 \\
交通银行 & -6.09 & -4.70 & -1.19 & -3.69 & -0.61 & 3.30 & 7.32 & 5.14 & 6.14 & -1.72 & 0.39 \\
中信银行 & 3.08 & 3.80 & 6.66 & 3.06 & 5.05 & 7.37 & 7.61 & 6.89 & 2.59 & -3.96 & 4.21 \\
宁波银行 & -6.64 & 1.36 & -0.94 & -8.34 & 6.35 & -0.64 & -3.83 & -2.90 & -4.39 & -9.39 & -2.94 \\
南京银行 & -21.34 & -17.31 & -16.62 & -24.65 & -0.18 & -2.46 & -0.38 & -7.23 & -16.25 & -14.68 & -12.11 \\
北京银行 & -3.02 & 3.31 & 3.18 & 1.15 & 0.13 & -1.02 & -1.72 & -3.89 & -5.73 & -0.07 & -0.77 \\
\hline
\end{tabular}

利率敏感性比率偏离度较大, 其计算公式为:

利率敏感性比率=利率敏感性资产/利率敏感性负债

偏离度 $=$ 利率敏感性比率 -1

从一家银行的利率敏感性分析表中可以看出一家银 行的经营状况。如果这家银行的利率敏感性大于零, 并且 一直处于升高的状态, 那么这家银行就应该处于提升利息 的状态中, 如果是对于处于相反状态中的银行, 那么就应 该利率敏感性片利率应该小于零。另外一种比较可能的策 略是通过将利率敏感性片利率控制在零左右, 这样就可以 增强银行的抵御风险的能力。

从数据中看, 招商银行是典型的风险控制银行, 南京 银行是较为进取的银行, 各大银行对于利息的升降也都有 着同的态度。

\section{3. 我国商业银行利率风险管理对策}

\section{1. 强化利率风险管理意识}

利率风险管理意识是风险管理的基础, 而现代商业银 行尤其是我国商业银行在风险管理意识方面仍有很大的 提升空间。这可能是因为长期以来的利率管制导致的, 也 与银行内部缺乏培训与专业培养有关。

首先应该建立完备的培训系统, 对于利率风险意识进 行强化。利率风险是当代商业银行必不可少的风险管控。 要引入专门的培训, 对于风险管理部门进行严格专业的培 训, 让管理人员和决策人员能够真正对于利率风险有意识, 有方法, 能够做出正确的决策。另外培训还应该包括对于 利率风险的数据判断和基本理论, 从报表上正确看待利率 风险, 从而为预防利率风险做出准备。

第二要建立基层员工的风险管理意识, 从对于数据的 准确收集到对于政策敏锐嗅觉, 都需要基层员工完成最为
基本的一部, 也只有建立完善的利率风险数据收集体系, 才能将商业银行看做一个整体来抵抗利率风险。

\section{2. 引入国际先进的利率风险管理体系}

事实上国外对于利率市场化的研究比我国早得多, 也 因此国外银行对于利率风险管理也更加具有经验, 有着更 加先进的利率风险管理模式。因此引进国际先进的利率风 险管理模式是防止快速提升商业银行风险抵抗能力的一 种方式。引进国际先进的利率风险管理模式主要包括以下 几个方面:

首先必须将利率风险管理作为风险管理中的重中之 重。资产负债表是利率风险管理的重要参考, 通过根据资 产负债表调节银行的利率政策, 从而更好的抵御利率风险, 是商业银行更好的抵御利率风险的必由之路。全面提升商 业银行的风险管理能力。

第二利率风险虽然是风险, 但是风险是可以预测的, 利率风险的预测可以使用很多模型来预测, 商业银行要选 取合适自己的风险管理模型来预测利率风险, 同时也有可 以聘请专业人员对于当前的市场情况作分析调研以及经 营状况做出评价, 正确预计利率风险以及利率风险可能的 影响, 为银行未来的经营做出准备, 帮助管理层更好的决 策。

目前我国利率市场化正处于快速发展的阶, 研究由中 国特色的利率市场化问题也是当前我国必须面临的问题, 如果能够最快速的找到适合我国国情的利率风险预测模 型那么无论是学术价值还是商业价值都无可估量。 


\section{3. 完善利率风险管理专业人才引进和培养模式}

无论是那种行业, 人才的培养都是十分重要的, 人才 是一家企业经营的最基本资本。如果想要真正做到正确预 防利率风险, 就必须引进一批真正对于利率风险有认知, 接受过专业培训的人才。同时要求将理论结合实际, 运用 到工作中, 及时准确预测利率风险, 尤其是对于我国这样 利率市场化起步较晚的国家来说, 更应该重视利率风险人 才的培养。我国加快利率风险管理人才的培养, 中国商业 银行急需要培养一支能够系统掌握并且灵活运用先进的 利率风险管理技能与方法的人才队伍。

风险管理在银行资产负债管理中的核心地位。设立专 门的利率风险管理部门, 重新确立利率风险管理机构的地 位和作用, 培养一批掌握并能灵活运用现代利率风险管理 技术的高素质人才, 严格执行风险管理程序, 加强银行内 部控制, 提升利率风险的管理能力。

除此之外, 建立利率风险人才培养模式也十分重要, 利率分析按专业人才的培养不仅仅是在学校的理论学习, 还包括进入共组后的一系列后续学习, 引进先进的利率风 险管理人员培训体系, 还包括对于不同学历、不同工作经 验的人的培养和晋升机制。也只有这样，才能真正使得利 率风险可以被控制。

\section{4. 营造良好的宏观金融环境}

正是因为利率逐步实现了市场改革, 才更需要完善的 金融监管体系, 才能使利率市场化符合市场规律, 才能使 商业银行能有效的应对利率市场化。

首先, 政府部门应该转变监管理念。利率市场化以后 的监管方式与之前完全不同, 高息揽存等等原来的一系列 错误行为现在成为了市场化的一部分。对于利率市场化带 来的金融产品创新相关部门要给予鼓励, 对于一些事实程 度较好的金融产品要给予支持。

第二要加紧培育金融证券以及货币交易市场, 开发金 融衍生产品。商业银行的利率风险除了正确预测、加紧预 防意外，还可以通过一些金融工具进行分散，同时也使得 金融市场更加活跃，更加具有抗风险能力。同时也使得商 业银行抵御利率风险的方式更加灵活。

\section{4. 结论}

在我国当前的金融大环境下, 利率风险是利率市场化 改革条件下不得不面临的问题, 也正是因为如此, 利率风 险问题也显得更加严峻。通过Eviews软件分析建立了数学 模型, 预测了在我国当前利率风险的定量大小以及利率敏 感性问题，通过数据分析建模等多种方式针对我国当前的 利率风险问题提出了强化利率风险管理意识、引入国际先 进的利率风险管理体系、完善利率风险管理专业人才引进
和培养模式、完善利率风险管理专业人才引进和培养模式、 营造良好的宏观金融环境等多建议, 为我国商业银行的发 展提供了一定的参考。

\section{参考文献}

[1] 王晋斌, 于春海. 中国利率市场化改革的可能路径 [J]. 金融 研究, 2007, 12:79-87。

[2]武剑. 利率市场化进程中的利率风险管理 [J]. 财经科 学, 2003, 02:58-63。

[3] 邵伏军. 利率市场化改革的风险分析 [J]. 金融研 究, 2004, 06:90-103。

[4] 肖欣荣, 伍永刚. 美国利率市场化改革对银行业的影响 [J]. 国际金融研究, 2011, 01:69-75。

[5] 郭慧宇. 基于EGARCH模型的我国商业银行同业拆借利率风 险研究 [D]. 浙江财经大学, 2014。

[6] 钱聿瑾. 我国商业银行的利率风险研究一一基于利率市场 化视角 $[D]$. 浙江大学, 2015。

[7］谢四美. 商业银行利率敏感性缺口与利率风险防范——基 于上市银行的实证分析 [J]. 金融论坛, 2014, 02:11-19。

[8] 廖理, 李梦然, 王正位. 聪明的投资者: 非完全市场化利率与 风险识别一一来自 P2P 网络借贷的证据 $[\mathrm{J}]$. 经济研 究, 2014, 07:125-137。

[9] 牛晓健, 雸翔. 利率与银行风险承担一一基于中国上市银行 的实证研究 [J]. 金融研究, 2013, 04:15-28。

[10］李春红, 董晓亮. 我国商业银行利率风险管理的实证研究 [J]. 华东经济管理, 2012, 04:88-92。

[11] 李颖. 利率市场化条件下的利率风险及其压力测试 [J]. 金 融论坛, 2012, 02:43-48。

[12] 陈昆, 高吴. 商业银行利率市场化风险分析-一以5家股份 制商业银行为例 [J]. 经济理论与经济管理, 2010, 03:57-61。

[13] 刘小艳. 利率市场化下商业银行的利率风险控制研究 [D]. 河北经贸大学, 2014。

[14] 王㓞. 利率市场化背景下城市商业银行利率风险实证分析 及对策研究 [D]. 山东财经大学, 2014。

[15] 郭鹏武. 利率市场化条件下商业银行利率风险管理研究 [D]. 山西财经大学, 2014。

[16] 吴炳辉, 何建敏. 中国利率市场化下的金融风险理论 [J]. 财 经科学, 2014, 03:1-10。 